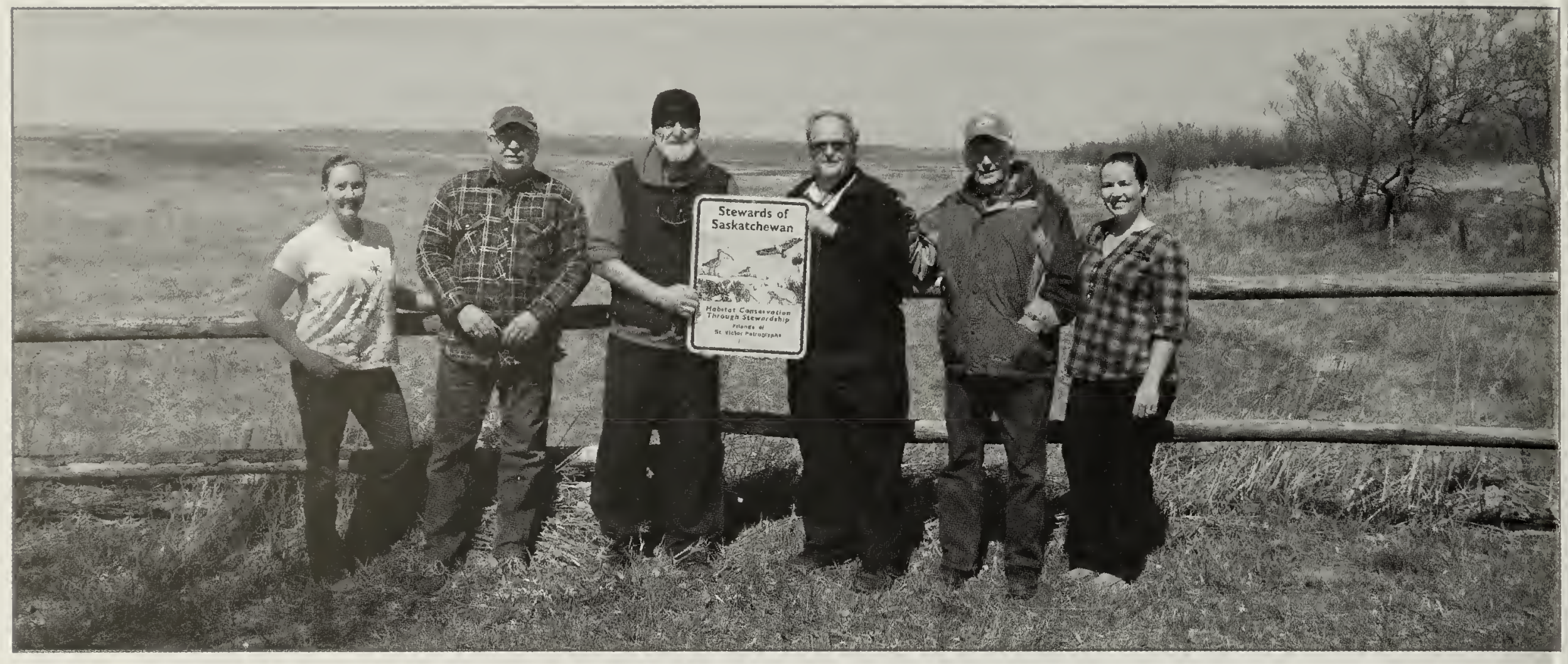

Stewards of Saskatchewan staff present Friends of the St. Victor Petroglyphs their personalized gate sign. From left to right: Ashley Fortney, Kevin Schauenberg, Wes Bloom, David Munro, Ernest Bissonnette, and Kaytlyn Burrows. Photo credit: Rebecca Magnus

\title{
FRIENDS OF THE ST. VICTOR PETROGLYPHS HELP SAVE MONARCH BUTTERFLIES
}

Ashley Fortney Habitat Stewardship Coordinator, Nature Saskatchewan

This past Earth Day, Stewards of Saskatchewan staff were glad to have the opportunity to get out of the office for a short trip to St. Victor, Saskatchewan. We met with new Stewards of Saskatchewan participants - the Friends of the St. Victor Petroglyphs. In attendance were members Wes Bloom, Kevin Schauenberg, Earnest and Yolanda Bissonnette, as well as the president, David Munro. The Friends recently joined Nature Saskatchewan's Stewards of Saskatchewan banner program, which works with interested landowners and land managers to conserve and enhance habitat for species at risk on the prairies — and the Friends fit right in! The Friends of the St. Victor Petroglyphs is a non-profit cooperative group whose main goal is to preserve, protect and promote the St. Victor Petroglyphs. They are also working hard to raise awareness around the importance of the diversity of species in the area and the need to conserve the habitat within the valley. The area is quite unique with coulees up to 300 feet deep, large swaths of undisturbed native vegetation full of spring beds, and an elevation that rises from 2,200 feet to nearly 3,000 feet in approximately 2 miles The area contains rare and beautiful

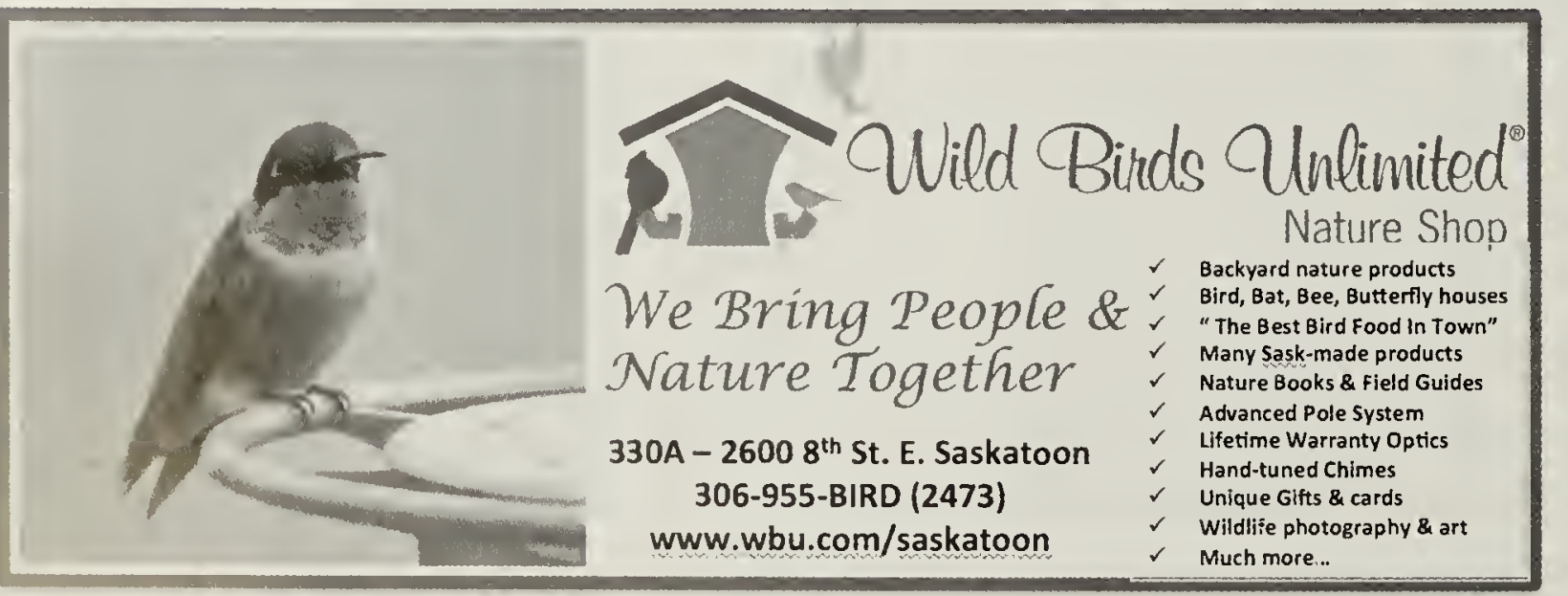

vegetation, including flowers such as White Paint Brush, Camus, Blazing Star, and even a tiny fern.

The Friends endorse St. Victor Petroglyph Provincial Park, and locally run Sylvan Valley Regional Park, as an ideal place for the introduction of nature hikes and tours within the deep coulees of the Wood Mountain Plateau. They also suggest this area could be used for people who want to study and record butterflies. They have a soft spot for one butterfly in particular — the Friends are participating in the protection and monitoring of monarchs. David told us, historically, the interpretative centre honours the Plains Grizzly as the "monarch of the prairies," and joked that the Friends have honoured such a large monarch for so long, they felt it was time to honour a small monarch as well! In case anyone is wondering, he immediately apologized for the pun.

Recent growing attention on monarch butterflies has shed light on the potentially grim future for the species, spurring many organizations to take action. The Friends believe 
